\title{
Biblioteca pública no Brasil: políticas federais de 1990-2006 ${ }^{1}$
}

\author{
Marília de Abreu Martins de Paiva
}

\begin{abstract}
Bibliotecária-Professora Assistente na Escola de Ciência da Informação. Doutoranda no Programa de Pós-Graduação da ECI/UFMG.
\end{abstract}

Maria Eugênia Albino Andrade

Doutora em Ciência da Informação; Professora Aposentada da ECI/UFMG.

http://dx.doi.org/10.1590/1981-5344/2278

As bibliotecas públicas tem sido objeto de discussões e políticas governamentais em todo o mundo, principalmente na chamada era da informação. No Brasil, elas estiveram presentes no discurso de políticas públicas governamentais desde a redemocratização do país, em fins do século XX. A análise dessas políticas demonstra que não foi possível ainda prover o básico: não existe ainda, finda a primeira década do século seguinte, pelo menos uma biblioteca em cada município do país. O fracasso dessa meta básica pode ser explicado por questões conceituais, direcionamento dos investimentos, inconsistências nos marcos legais, distribuição de funções entre os agentes institucionais, falta de formação de pessoal para a implementação das políticas, além de problemas estruturais e arraigados da forma de fazer política no Brasil, que se mantém ao longo dos governos, ditatoriais ou democráticos. O Plano Nacional do Livro e da Leitura, lançado no final do ano 2006, se apresenta com um discurso inovador cuja implementação real, contudo, não faz parte desse estudo.

Palavras-chave: Biblioteca pública. Política pública. Brasil.

\footnotetext{
${ }^{1}$ Estudo originalmente publicado como dissertação de mestrado (PAIVA, 2008).
} 


\section{Public library in Brazil: federal policies 1990-2006}

The public libraries have been the subject of discussions and government policies around the world, especially in the information age. In Brazil, they were present in the discourse of government policies since the democratization of the country in the end of twentieth century. The analysis of these policies demonstrates that still wasn't possible to provide the basics: there isn't yet, at the end of the first decade of the next century, at least one library in each city of the country. The failure of the basic goal can be explained by conceptual questions, directing investments, inconsistencies in the legal guides, distribution of functions between institutional agents, deficiency training of staff for the implementation of policies, also structural and entrenched problems of how to make policy in Brazil, which remains over the governments democratic or dictatorial. The Plano Nacional do Livro e da Leitura, initiated at the end of 2006, presents an innovative discourse which actual implementation, however, is not part of this study.

Keywords: Public Library. Public policy. Brasil.

Recebido em 19.11.2014 Aceito em 20.11.2014

\section{Introdução}

A Sociedade da Informação traz, em seu bojo, a grande discussão sobre o acesso à informação. Uma discussão que já fazia parte dos questionamentos da biblioteca pública, principalmente desde o final do século XIX, quando a biblioteca passa a ser vista como complementar a educação, que é a base fundamental da democracia (SEAVER ${ }^{2}$ apud MUELLER, 1984). Com maior vigor ainda, desde a década de 1960, a biblioteca pública passa a assumir também o papel de prestadora de serviços aos carentes e minorias (CURLEY ${ }^{3}$ apud MUELLER, 1984). A questão sobre o financiamento governamental da biblioteca também acompanha as discussões sobre a função da biblioteca pública, e é fortemente retomada no mundo globalizado da Sociedade da Informação, que preconiza novas posturas para o Estado.

\footnotetext{
2 SEAVER, Benjamim. Message of the mayor on the subject of a Public Library, February 19, 1852. City Document n. 10. Boston: No publisher, 1852.

${ }^{3}$ CURLEY, Arthur. Social responsibility and libraries. In: VOIGGT, Melvin J. (Ed.). Advances in Librarianship. New York: Academic Press, 1974. v. 4, p. 77-101.
} 
Dentro dessa perspectiva, acompanhamos os trabalhos de Nogueira (1985), que reflete sobre a contradição do papel da biblioteca pública na sociedade capitalista; de Barros (2002), que discute a contribuição social da biblioteca pública para o cidadão; e, principalmente, de Araújo (2002) e de Oliveira (1994), que estudam as ligações entre o Estado brasileiro por meio de suas políticas - e as bibliotecas públicas, cobrindo praticamente todo o período republicano até o fim da década de 1980 , o presente trabalho é uma pesquisa de base documental, concretizada por meio de análise de conteúdo e histórica das políticas relacionadas às bibliotecas públicas no Brasil, entre 1990 e 2006. Os principais documentos considerados foram as leis, decretos e outros, emitidos pelo próprio governo federal e seus departamentos, envolvidos na formulação e execução das políticas de bibliotecas públicas. Além desses, foram utilizados outros documentos originados fora do âmbito governamental, que de algum modo tenham expressado uma reação ou avaliação daqueles documentos e ações. A decisão de não se fazer comparação estatística dos resultados das ações governamentais decorre das seguintes constatações: falta de tradição do País em manter registros metódicos, na área da cultura; grande mudança institucional que cada governo estabelece nas entidades governamentais; e descuido com os arquivos governamentais. Algumas vezes, foram utilizados dados de relatórios governamentais, mas verificou-se durante o trabalho grande incoerência e inconsistência dos registros, até mesmo em dados descritivos.

\section{Biblioteca Pública}

Através da história, a biblioteca evoluiu e suas funções foram transformadas paralelamente às transformações das sociedades, incluindo aí as diferentes tecnologias que passaram a dar suporte à informação, desde as gravações de som e imagem às Tecnologias de Informação e Comunicação (TICs), cada vez mais presentes desde o final do século XX. A mudança de concepção da célula da biblioteca (não mais unicamente o impresso, mas também outros suportes da informação, sobretudo os eletrônicos) está se dando em grande velocidade, mas de forma muito desigual nos espaços e nas sociedades, permanecendo ainda, no senso comum e no imaginário popular, como uma coleção de livros. Mueller (1984), em sua abrangente revisão sobre a evolução das funções e papéis da biblioteca na sociedade, demonstra como a instituição biblioteca não é (e nunca foi) uma entidade independente: seu papel e as formas de desempenhá-lo se encaixam nos limites impostos pelo seu contexto social, cultural, moral, econômico, político e tecnológico. Nosso estudo diz respeito à função e atribuições de um tipo específico de biblioteca: a biblioteca pública.

É no século XIX, com a consolidação dos ideais democráticos, com o desenvolvimento industrial e o crescimento da urbanização que emergem as bibliotecas públicas comos questionamentos que permanecem até hoje: sua função social, seus objetivos e seu financiamento. Para Cesarino 
(2007, p. 11) "bibliotecas são instituições muito antigas que sobrevivem há anos, adaptando-se às diversas mudanças políticas, sociais e tecnológicas. Essa sobrevivência, por si só, já é suficiente para provar que cabe à biblioteca uma função muito importante na sociedade". Almeida Júnior (2003), contudo, chama a atenção para o fato de que a função social da biblioteca pública deverá, sempre, ser colocada em cheque, por meio de avaliações.

Em estudo crítico de base marxista sobre as bibliotecas públicas, Cecília Nogueira busca enfatizar seu caráter contraditório na sociedade capitalista: instrumento auxiliar de democratização do saber e da construção de uma nova composição social, por um lado; e, por outro, instituição que funciona sob censura e controle do Estado, como recurso técnico de inculcação da ideologia da classe dominante. Esse caráter contraditório da biblioteca pública leva ao cumprimento de papéis também ambivalentes: "ao mesmo tempo (em) que auxilia a conservação da hierarquia de classes, contribui para a superação da relação de dominação" (NOGUEIRA, 1985, p. 97).

As bibliotecas públicas, de uma forma ou de outra, sempre tiveram, como funções básicas, a coleta, a conservação, a organização e a difusão de informações, e têm buscado, através da difusão do conhecimento (MUELLER, 1984), a produção de um bem social. A instituição nunca se dissociou da educação, seja no apoio à educação formal, seja, sobretudo, como espaço de aprendizagem contínua (CUNHA, 2003), embora a sua escolarização seja destacada como um problema, não só por esse autor como por Milanesi (1993) e Suaiden (2000). No século XVIII, com a introdução das primeiras reformas para a instrução pública, principalmente em países protestantes, e, posteriormente, com a Revolução Francesa, a ideia de uma "biblioteca para todos" se apresentou. Mas foi no mundo anglo-saxão que a relação biblioteca/sociedade passou a valer de fato (SERRAI, 1975). Mais tarde, nos séculos XIX e XX, nos Estados Unidos, filantropos capitalistas (LEMOS, 2005) fundaram e sustentaram bibliotecas públicas. Para Moraes, essa biblioteca pública aberta, no sentido que hoje se tem, desenvolveu-se com as ideias democráticas norte-americanas e é uma das contribuições mais relevantes dos Estados Unidos à cultura universal (MORAES, 2006, p. 97).

A partir de meados do século XIX, as bibliotecas públicas passaram a ser consideradas instrumento auxiliar do processo formal de educação e "um dos mais democráticos mecanismos de realização da chamada educação permanente" (LEMOS, 2005). Raymond Irwing, na segunda metade do século $X X$, chamava a atenção para a independência que deveria haver nas bibliotecas, o que, segundo ele, passaria pela separação delas da administração direta do Estado - mas não, talvez, de sua subvenção (IRWIN ${ }^{4}, 1950$ apud MUELLER, 1984). A discussão sobre o que deveria ser promovido pelas bibliotecas públicas sempre reportava à

\footnotetext{
${ }^{4}$ IRVIN, Raymond. The library services in the welfare estate. In: GERARD, David, ed. Libraries in society: areader. London, Clive Bingley, 1978. p. 21-26. Originally published: Library World 53(8). Aug./Sept.1950.
} 
questãode seu financiamento. A popularização de seu acervo, por exemplo, foi criticada no início do século XX, nos Estados Unidos, pois, sendo mantida pelo poder público, deveria oferecer acervo de melhor gosto, pois, infelizmente, as pessoas não estavam lendo "(...) o tipo certo de livro. A biblioteca (deveria) dedicar-se a remediar esse mal, utilizando, para tanto, quaisquer meios que se (mostrassem) necessários" (BATTLES, 2003, p. 153). Herbert Putnam, da biblioteca do Congresso Americano, respondeu às críticas de popularização do acervo e da biblioteca com um pronunciamento lapidar: "A biblioteca pública não lida apenas com estudantes se preparando para a vida, mas com homens e mulheres vivendo suas vidas" (PUTNAM ${ }^{5}, 1915$ apud MUELLER, 1984). Ele propunha que os bibliotecários fizessem intervenções pessoais com os usuários, influenciando, mas não "distribuindo o bom gosto". Quando a biblioteca deixou de ser prioritariamente educativa, para ocupar também um lugar de lazer, muitos se opuseram, por considerar errado financiar o lazer com dinheiro público (MUELLER, 1984).

A partir de meados da década de 1960, segundo Lemos, dois aspectos beneficiaram as bibliotecas públicas, pelo menos na Europa: o "revivalismo das ideias de democratização da cultura" e, na esteira da euforia econômica, "o advento do Estadodo bem-estar social (welfarestate)" (LEMOS, 2005, p. 106). Hoje, se a ideia de biblioteca pública mantida pelo poder público parece ser menos controversa, por outro lado, muitas vezes, a opção dos governos tem sido a de investir no topo, isto é, nas bibliotecas especializadas e nos "programas de informação científica, por vezes colocados na esfera das prioridades" (MILANESI, 1993, p. 90), no que ele chamou de "construção sem alicerces" e Suaiden (2000) chamaria de "inversão de valores".

A partir da década de 1990 outras questões impulsionaram a retomada da discussão sobre as bibliotecas públicas: a discussão, nos fóruns mundiais, sobre o desenho de uma nova sociedade global, a Sociedade da Informação, as questões colocadas pelas TICs, a inclusão social, a competência informacional, $o$ analfabetismo funcional e os "serviços bibliotecários como estratégia para o desenvolvimento de comunidades letradas e informadas" (CESARINO, 2007, p. 42).

No contexto internacional, o Manifesto da Unesco sobre bibliotecas públicas, publicado em 1994, preconiza doze missões para as mesmas na nova realidade de final do século $X X$ : criar e fortalecer hábitos de leitura nas crianças desde a mais tenra idade; apoiar tanto a educação individual e autodidata como a educação formal em todos os níveis; proporcionar oportunidades para o desenvolvimento criativo pessoal; estimular a imaginação e criatividade da criança e dos jovens; promover o conhecimento da herança cultural, apreciação das artes, realizações e inovações científicas; propiciar acesso às expressões culturais das artes em geral; fomentar o diálogo intercultural e favorecer a diversidade cultural; apoiar a tradição oral; garantir acesso aos cidadãos a todo tipo

5PUTNAM, Herbert. "Per contra". In: MCCRIMMON, Barbara (Ed.). American libraryphilosophy: an anthology. Hamden, Conn, ShoeString, 1975. p. 39-50. Originally published Library Journal 40. July 1915. 
de informação comunitária; proporcionar serviços de informação adequados a empresas locais, associações e grupos de interesse; facilitar o desenvolvimento da habilidade no uso do computador; apoiar e participar de atividades e programas de alfabetização para todos os grupos de idade e implantar tais atividades se necessário. Nesse documento também são explicitados a natureza e os propósitos ideais de tais bibliotecas:

A biblioteca pública é o centro local de informação, tornando prontamente acessíveis aos seus utilizadores o conhecimento e a informação de todos os gêneros. Os serviços da biblioteca pública devem ser oferecidos com base na igualdade de acesso para todos, sem distinção de idade, raça, sexo, religião, nacionalidade, língua ou condição social. Serviços e materiais específicos devem ser postos à disposição dos utilizadores que, por qualquer razão, não possam usar os serviços e os materiais correntes (...). Todos os grupos etários devem encontrar documentos adequados às suas necessidades. As coleções e serviços devem incluir todos os tipos de suporte e tecnologiasmodernas apropriadas assim como fundos tradicionais. É essencial que sejam de elevada qualidade e adequadas às necessidades e condições locais. As coleções devem refletir as tendências atuais e a evolução da sociedade, bem como a memória da humanidade e o produto da sua imaginação. As coleçõese os serviços devem ser isentos de qualquer forma de censura ideológica, política ou religiosa e de pressões comerciais (IFLA/UNESCO, 1994).

Suzana Sperry (1993), já chamara a atenção para a função que a biblioteca pública poderia ter como instituição líder de movimentos culturais, desde que revisse seu próprio papel. A autora destacou ainda a grande contribuição desse tipo de biblioteca para diminuir os efeitos da massificação sobre os indivíduos, pois os livros fariam desacelerar a oralidade e a instantaneidade dos meios de comunicação, que isola as pessoas e as restringe à comunicação oral.

Em 1998 a União Européia publicou o seu Relatório ${ }^{6}$ sobre o papel das bibliotecas na sociedade moderna (UNIÃO EUROPÉIA, 1998). O relatório levou em consideração vários documentos da União Européia, entre eles, o relatório "Construir a Sociedade da Informação para todos"', considerando diversos pressupostos, dentre eles: a importância do domínio da informação como fator de integração econômica das pessoas; a importância da cultura no desejo e aquisição de novos conhecimentos e de enriquecimento linguístico, sobretudo através da literatura; a relevância das dimensões democrática, social e cultural na evolução da sociedade, e não apenas as dimensões econômicas e tecnológicas; a

\footnotetext{
${ }^{6}$ Cuja relatora foi a deputada MirjaRyynanen, da Finlândia.

7 Citado sem referência no Relatório A4-0248/98.
} 
necessidade de manutenção do adequado equilíbrio entre os direitos e interesses em jogo na Sociedade da Informação; a importância de se garantir o acesso à crescente quantidade de informação disponível em rede; o papel insubstituível das bibliotecas na organização do acesso ao conhecimento e na mediação entre os meios informacionais tradicionais e os novos; o lugar que as bibliotecas podem ocupar formando uma rede de transmissãode conhecimento e cultura comparável às escolas; e a contribuição única das bibliotecas como instituição de apoio à aprendizagem ao longo da vida. Além disso, o relatório também salientou a importância das bibliotecas do ponto de vista cultural, para manter um nível geral de competência na leitura; manter vivas a língua, a literatura e a cultura do país; transferir os dados relativos ao patrimônio cultural para um formato digital; e proporcionar uma "janela única" e intelectualmente enriquecedora "em relação a outras culturas e modos de vida" (UNIÃO EUROPÉIA, 1998). A conclusão é que as bibliotecas são um elemento crucial do processo do fenômeno relacionado com a Sociedade da Informação, e que ocuparão um lugar mais importante na Sociedade da Informação do que tinham (na) sociedade industrial.

No Brasil, a Fundação Biblioteca Nacional (2000, p. 18), agente do Sistema Nacional de Bibliotecas Públicas, publicou documento em que define as seguintes características básicas das bibliotecas públicas: destinar-se a toda coletividade (ao contrário de outros tipos de bibliotecas, que têm funções mais específicas); possuir todo tipo de material (sem restrições de assuntos); ser subvencionada pelo poder público federal, estadual ou municipal. Além das características e missões citadas, destacam-se, ainda, as seguintes funções institucionais: agente essencial na promoção e salvaguarda da democracia, através do livre acesso a todo tipo de informação proporcionando, desta forma, matéria de reflexão para a geração do verdadeiro conhecimento; instituição de apoio à educação e formação do cidadão em todos os níveis, através da promoção e incentivo à leitura e à formação do leitor crítico e seletivo capaz de usar a informação como instrumento de crescimento pessoal e transformação social; centro local de tecnologias da informação, através do acesso às novas tecnologias da informação e da comunicação, familiarizando os cidadãos como seu uso; e instituição cultural, através da promoção do acesso à cultura e do fortalecimento da identidade cultural da comunidade local e nacional (FUNDAÇÃO BIBLIOTECA NACIONAL, 2000, p. 22).

Em Portugal, no ano 2000, aconteceu a Conferência Internacional Bibliotecas Públicas: Inventando o futuro. $\mathrm{Na}$ oportunidade foram ressaltadas as dimensões democráticas, educacionais e culturais das bibliotecas públicas. Hapel (2000) reforçou os seguintes valores básicos de bibliotecas públicas que, para ele, realmente deveriam ser comuns em todo o mundo: assegurar o acesso livre e igualitário à informação e ao conhecimento; assegurar a formação livre de opinião; fortalecer a habilidade de leitura; levar adiante a disseminação cultural; fortalecer as habilidades criativas e analíticas pessoais; apoiar a diversidade cultural; e fortalecer o conhecimento das novas possibilidades tecnológicas. Para 
Hapel, o papel dos profissionais das bibliotecas em nosso tempo é ajudar os usuários a encontrar soluções para seus próprios problemas, o que não se dará apenas com o acesso a informações "frias" mediadas pelas TICs. MacDermott (2000), levando em conta as mudanças tecnológicas em curso, salientou que os serviços das bibliotecas no futuro serão tanto os tradicionais quanto novos serviços avançados que as tecnologias possibilitam e mais ainda possibilitarão. Ryynanen, relatora do citado documento da União Européia (2000) lembra que, independente das diferentes mídias, as funções sistemáticas típicas das bibliotecas de adquirir, organizar, preservar e oferecer para uso os registros não foram cumpridas por nenhuma outra instituição, em toda a história.

\section{As políticas governamentais do Estado brasileiro para as bibliotecas públicas de 1990 a 2006}

O final da década de 1980 coincide, no Brasil, com a volta ao Estado de direito, com o amadurecimento dos movimentos pela redemocratização e com o início da disseminação do discurso da Sociedade da Informação. Em busca de uma nova configuração de Estado, desvinculada das instituições dos governos da República até então, e, principalmente, dos governos militares da recentemente finda ditadura, os governos civis, desde a década de 1990, empreenderam, sem cessar, mudanças na estrutura administrativa. Assim foram criados, extintos e renomeados: ministérios, secretarias, autarquias, fundações, empresas públicas e de economia mista e todo tipo de instituições e programas ligados ao governo federal. De 1990 a 2006, quatro governos se sucederam, mudando nomes de programas, projetos e departamentos, lançando diferentes campanhas em nome do livro, da leitura e da biblioteca. As políticas de informação científica e tecnológica correram em raia separada, com investimentos mais concentrados e notáveis, buscando e constituindo resultados mais significativos e palpáveis.

O retorno ao Estado de direito no Brasil, na década de 1980, possibilitou que a sociedade pudesse posicionar-se, pronunciar-se e pressionar os governos - não sem disputas entre os grupos sociais - para que suas demandas fossem atendidas ou, minimamente, ouvidas. Se por um lado grupos com maior capacidade de se pronunciar certamente têm mais chance de se fazerem ouvir, por outro, a experiência da democracia e sua conseqüente consolidação, cada vez mais, abre as possibilidades de discussão e reflexão, numa espiral, crê-se, ascendente.

Há muito tempo as questões hoje emergentes da sociedade da Informação já foram postas pelas bibliotecas: o acesso, a utilização e a produção de informação pelo maior contingente de cidadãos, a formação para a vida, a educação permanente. A disputa, nas políticas públicas, acontece na arena da sociedade e revela seus atores, para além da estrutura governamental. Enumeramos, sumariamente ${ }^{8}$, a seguir, a

\footnotetext{
${ }^{8}$ Cada governo e seus respectivos feitos em relação aos livros, leitura e bibliotecas estão descritos em PAIVA (2008), referenciado no fim do artigo.
} 
seqüência de governos federais eleitos diretamente pela população brasileira, e os principais marcos legais relacionados à questão das bibliotecas públicas.

Fernando Collor de Melo: 1990-1992 (afastado por impeachment) 1990 - Lei 8.028 - Extingue o Ministério da Cultura e o substitui pela Secretaria da

\section{Cultura.}

1991 - Lei 8.313: Lei Rouanet, principal ferramenta de fomento à cultura, via renúncia fiscal dos patrocinadores.

1992 - Lei 8.029: extingue o Instituto Nacional do Livro (INL, dentro da Fundação.

Pró-Leitura) e cria a Fundação Biblioteca Nacional (FBN).

1992 - Dec. 99.240: extingue a Fundação Nacional Pró-Leitura (desdobramento da

Lei 8.029).

1992 - Dec. 519: cria o Proler (Programa Nacional e Incentivo à Leitura).

1992 - Dec. 520: cria o Sistema Nacional de Bibliotecas Públicas (SNBP) dentro da FBN.

\section{Itamar Augusto Cautieiro Franco: 1992-1995}

1992 - Lei 8.490: Recria o Ministério da Cultura (MINC)), sem, contudo, reestabelecer a estrutura anterior.

Fernando Henrique Cardoso: 1995-2002 (2 mandatos)

(PRONAC).

1995 - Dec. Lei 1.494: Programa Nacional de Apoio à Cultura

1996 - Programas "Uma biblioteca em cada município", do MINC e "Livro Aberto" da FBN.

1999 - Dec. 3.049: aprova a estrutura e os cargos do Ministério da Cultura, tendo em sua estrutura a Secretaria do Livro e da Leitura (SLL). 1999 - Dec. 3.294: Sociedade da Informação.

2000 - Livro Verde da Sociedade da Informação.

2001 - Regimento do Conselho Nacional de Incentivo à Cultura (CNIC).

2002 - Cadastro Nacional de Bibliotecas (CNB).

\section{Luís Inácio Lula da Silva: 2003-2006 (1ำ mandato)}

2003 - Extinção da Secretaria Nacional do Livro e da Leitura.

2003 - Novo estatuto da FBN.

2003 - Lei 10.753: Institui a Política Nacional do Livro.

(CSLLL).

2004 - Criação da Câmara Setorial do Livro, Literatura e Leitura

2004 - Programa Fome do Livro.

2004 - Portaria 234 MINC: Institui o Grupo de Trabalho do livro e da leitura para formular a Política Nacional do Livro, Leitura e Bibliotecas. 
2004 - Lei 11.033: Decreta a desoneração do PIS/Cofins para o livro.

2005 - Ano Viva leitura.

2005 - Lei 11.116: Complementa a lei anterior e permite a utilização dos créditos do

PIS/Cofins.

2005 - Emenda Constitucional 48, institui o Plano Nacional da Cultura.

2006 - Lançamento do Plano Nacional do Livro e da Leitura (PNLL), com texto e objetivos, em 13 de março.

2006 - Portaria Interministerial 1442 - Institucionalização do PNLL, (agosto).

2006 - PNLL: texto programático conceitual (dezembro).

\section{Análise}

Apontamos, a seguir, os resultados da análise das políticas públicas para bibliotecas no período pesquisado. Propõe-se uma análise por categorias conceituais que foram elencadas durante a pesquisa teórica, mas, também construídas durante o próprio estudo das políticas no Brasil.

\section{A existência de bibliotecas}

Todos os programas voltados para as bibliotecas públicas, desde o governo Collor, tiveram como objetivo "incentivar a criação de bibliotecas em municípios desprovidos de bibliotecas públicas" (Proler), "prover cada município brasileiro com uma biblioteca pública" (Uma biblioteca em cada município), "implantar bibliotecas em cada município brasileiro" (Livro Aberto), "a abertura de bibliotecas públicas de qualidade em mais de mil municípios brasileiros que não possuem uma" (Fome de Livro), "zerar o número de municípios brasileiros sem biblioteca pública" (Quero ler Biblioteca para todos), a implantação de bibliotecas em todos os municípios do País (PNLL). Essa repetição, por si só, a despeito da extensão do País, representa o fracasso das políticas para bibliotecas públicas, que não conseguiram ainda prover o básico: tornar realidade as bibliotecas públicas em todo território.

Uma possível explicação a respeito dessas reedições do mesmo objetivo em documentos diferentes é a descontinuidade administrativa: cada governo preferiu não dar continuidade e aprimorar o programa existente, mas fazer um "novo", dar-lhe um novo nome, nomear outro diretor, sobrepondo objetivos e dispersando energia e recursos, além de desperdiçar todo o conhecimento acumulado, as relações estabelecidas, as experiências que evitam a repetição dos erros.

\section{Políticas para os livros ou para as bibliotecas?}

Embora bibliotecas e livros estejam intrinsecamente ligados, no desenvolvimento das políticas públicas nem sempre o beneficiamento de 
um significa o mesmo do outro. Desde o Instituto Nacional do Livro, os pesquisadores têm destacado que a política muitas vezes buscou beneficiar a cadeia produtiva do livro, e não propriamente o bem público por meio do desenvolvimento de serviços das bibliotecas. Também nos governos estudados a maioria das ações voltadas para as bibliotecas públicas teve como procedimento principal, quando não o único, o envio de acervo e, eventualmente de equipamentos (estantes, mesas e, às vezes, computador).

Os primeiros beneficiados com essa prática foram os editores, que já tem no governo federal o maior comprador de livros. Somente no governo Lula pode-se citar três leis diretamente relacionadas à produção e distribuição de livros: a chamada "Lei do livro", número 10.753, de2003; a 11.033 , de 2004; e a 11.116, de 2005. A primeira parte do pressuposto da supremacia do livro como meio insubstituível de difusão da cultura e do conhecimento, declara que o Estado pretende assegurar ao cidadão o pleno direito de acesso, e um dos possíveis pontos de acesso seriam as bibliotecas. Estabelece que o Poder Executivo implementará programas para manutenção e atualização do acervo de bibliotecas públicas e, nas disposições gerais, inova, ao retirar dos livros de bibliotecas públicas o caráter de bem permanente, providência útil para facilitar o desenvolvimento de coleções. As outras duas leis desoneram o produto livro de impostos e permitem a reutilização dos impostos pelas próprias editoras.

Não houve, em todo o período estudado, uma "Lei das Bibliotecas". Ao invés das leis do livro complementarem a política de bibliotecas, elas tornaram-se a política de bibliotecas. A prática da distribuição de livros, ainda que produza a realidade material do contato com o livro, não significa formar leitores. Além disso, periódicos e outros recursos são esquecidos, e nenhum estudo é feito para se conhecer as necessidades e desejos das comunidades que receberão o acervo, ou seja: a biblioteca, seu público, seus serviços, seu contexto social, são na maioria das vezes, ignorados.

\section{A concepção de biblioteca pública}

As bibliotecas estiveram presentes nos discursos oficiais em todo o período estudado, mas a concepção das bibliotecas públicas não foi de fato discutida. Basicamente, a biblioteca é o lugar onde ficam os livros. Nenhuma menção é feita aos serviços da biblioteca. A Associação de Amigos é promovida para garantir a possibilidade de apresentar projetos para as leis de incentivo, mas as formas de participação da comunidade na administração da biblioteca sequer são aventadas.

Ao contrário das discussões internacionais sobre o papel das bibliotecas na nova Sociedade da Informação, no Brasil o lançamento dos planos tem mais importância, do que deveriam ser as bibliotecas públicas em nosso país 
São apresentados dados numéricos sobre as carências do setor da leitura e das bibliotecas, mas não se discute a trabalhosa questão: "Que bibliotecas precisamos e queremos hoje, em cada município desse País"?

As próprias bibliotecas públicas, como conceito, foram retiradas dos títulos dos programas oficiais.

A partir de 2005, o chamado Ano Viva leitura, as "bibliotecas" deixam de figurar no título da proposta de política pública para a área, embora estivesse em vários documentos preliminares, o que significa que prevaleceu a política do livro, e as políticas desviaram-se da primazia e centralidade das bibliotecas como condição para o acesso à leitura.

Contudo, a sociedade civil se pronunciou naquele momento em que um importante marco legal era publicado, e deixava as bibliotecas públicas apenas na margem do Plano Nacional. O Manifesto do Povo do Livro, entregue ao Presidenteda República em 2006, após a instituição do PNLL, destacava, veementemente, a biblioteca pública como o "meio mais eficiente de proporcionar educação continuada à população e, dessa forma, ser instrumento de democracia e de política social" através de "bons e diversificados acervos de livros e de outros materiais; pessoal qualificado e estimulado; e recursos permanentes para manutenção, atualização, formação e fomento" (MANIFESTO, 2006).

\section{Os marcos legais}

Em todo o período estudado, vários marcos legais podem ser destacados nas políticas de bibliotecas. O período se inicia com o fim do Ministério da Cultura no governo Collor, em 1990, substituído, então, por uma Secretaria de Cultura. O principal impacto dessa mudança para as bibliotecas públicas foi o fim da Fundação Pró-Leitura, sob a qual estava o INL que, bem ou mal, as mantinham dentro da esfera governamental. No mesmo documento, era constituída a Biblioteca Nacional como Fundação. A Lei Rouanet, de 1991, marcou a história do fomento e custeio à cultura no Brasil, com dezenas de reedições e alterações, mas com o conceito fundamental intacto: o patrocínio a projetos culturais por parte das empresas privadas, por meio do estímulo financeiro da renúncia fiscal. Essa lei beneficiou pouco as bibliotecas públicas, em primeiro lugar, porque o número de projetos apresentados para elas foi reduzido; porém algumas Associações de Amigos das Bibliotecas conseguiram aprovar e executar vários projetos e, no âmbito nacional, a construção de um sistema para gerenciamento de bibliotecas, o BibLivre, totalmente gratuito e desenvolvido em software livre. Somente em 1992, contudo, os decretos no 519 e 520 marcariam o início de uma nova era para as bibliotecas públicas.

A instituição do Proler e do Sistema Nacional das Bibliotecas Públicas, dentro da Fundação Biblioteca Nacional, focaram dois aspectos fundamentais para o desenvolvimento das bibliotecas públicas: um lado a promoção, a disseminação e a integração de práticas de leitura; de outro, a estruturação de um sistema nacional que integraria as bibliotecas públicas dos estados, que, por sua vez, deveriam ramificar essa estrutura 
nos seus Municípios, descentralizando a política. Do ponto de vista da concepção, essa divisão faz sentido, coincidindo com a divisão que a própria Unesco faz entre fatores qualitativos (existência de leitores) e quantitativos (existência de pontos de acesso à leitura) para a formação de um país de leitores ${ }^{9}$.

No governo seguinte, de Itamar Franco, a recriação do Ministério da Cultura não foi significativa para o desenvolvimento das políticas para bibliotecas públicas. Se por um lado, o status de Ministério tem um significado simbólico e político para a área da cultura, no que concerne ao tema das bibliotecas públicas, os marcos legais não foram modificados, permanecendo o Proler e o SNBP sob a Fundação Biblioteca Nacional, na mesma estrutura, com os mesmos dirigentes. Porém com a recriação do Ministério a FBN foi se distanciando da direção das políticas públicas, com o crescimento de uma estrutura ministerial que a deixaria com menos poder para dirigi-las e executá-las.

A partir do governo Fernando Henrique Cardoso alguns programas específicos para bibliotecas públicas foram postos em prática, diretamente advindos do Ministério da Cultura, tendo sido o primeiro deles, uma biblioteca em cada município, que depois se juntou ao Livro Aberto. 0 primeiro vinculou-se ao MINC, que agora agregava a Secretaria do Livro e da Leitura, e o segundo à FBN. Curiosamente, ambos repetem, em seus objetivos, aqueles descritos no Proler e no SNBP, embora legalmente não os suprimam.

Outro marco do governo FHC, o Programa Sociedade da Informação, não incluiria as bibliotecas públicas dentre as estruturas prioritárias, mas sim como ferramenta auxiliar, principalmente como ponto de acesso às tecnologias de informação ecomunicação, não per si. O cadastro que o SNBP vinha construindo desde sua instituição, por exemplo, seria repassado ao MINC para compor o Cadastro Nacional de Bibliotecas, mas a FBN não teria lugar na direção e coordenação desse cadastro, que ficaria com o Ministério da Ciência e Tecnologia (MCT), casa original do Programa Sociedade da Informação. O MCT, por sua vez, daria prioridade às bibliotecas especializadas e universitárias, mais próximas de seu objetivo, e os recursos eletrônicos que o Programa Socinfo concretizou foram especificamente para esses dois tipos de bibliotecas.

A Fundação Biblioteca Nacional tem sua função ratificada no governo Lula, por meioda aprovação de um novo estatuto e quadro de cargos e funções O Proler e o SNBP continuam dentro de sua estrutura, com as mesmas funções, e a FBN tem, entre suas atribuições, a de subsidiar a formulação de políticas e diretrizes voltadas para a produção e ao amplo acesso ao livro. Essas funções, contudo, estão também sendo desenvolvidas dentro do MINC, primeiramente dentro da Secretaria Nacionaldo Livro e da Leitura e depois, especificamente dentro de uma

\footnotetext{
${ }^{9}$ Aqui relembramos a Lei da passagem da quantidade à qualidade (marxismo), segundo a qual há uma relação dialética entre quantidade e qualidade: por um lado "a mudança de qualidade depende, em determinado momento, da mudança de quantidade" e, por outro, a qualidade de uma coisa "está intimamente ligada à maneira de como as propriedades e os elementos [da coisa] estão estruturados". Ver TRIVINOS, Augusto Nibaldo Silva. Introdução à pesquisa em ciências sociais: a pesquisa qualitativa em educação. São Paulo: Atlas, 1992. p. 66.
} 
Câmara Setorial do Livro e da Leitura, que passa a liderar o espaço de discussão do livro e da leitura, entre Estado e sociedade.

Com a Lei do Livro, fica instituída nominalmente a Política Nacional do Livro, e não das bibliotecas que são apenas os lugares onde os livros ficarão. Contudo, o governo Lula apresenta ainda o Programa Fome de Livro, em 2004, como um meio de o governo coordenar os esforços governamentais e da sociedade civil em prol das bibliotecas públicas e da leitura. O programa também repetia os esforços do SNBP, ao conduzir a criação de bibliotecas públicas onde elas não existissem, e do Proler, ao fomentar a participação de outros atores sociais, ações e projetos na área do livro, da leitura e das bibliotecas.

A novidade, de fato, foi a participação dos outros níveis de governo e de outros ministérios, embora também o Proler também tenha se aproximado muitas vezes do Ministério da Educação, por exemplo.

No embate das discussões, contudo, ao que parece, a área das bibliotecas não conseguiu se impor, pois no mesmo ano a Portaria do MINC instituiu o Grupo de Trabalho GT do Livro e da Leitura, sem as bibliotecas no nome, embora em seus objetivos a criação de bibliotecas públicas se mantivesse.

O GT seria composto por três membros de Secretarias do MINC e um apenas da FBN, quando se justificavam pelo menos dois: um do SNBP e outro do Proler.

Em agosto de 2006, a portaria que institui o PNLL se destaca entre os marcos legais, por ser uma Portaria Interministerial dos Ministérios da Cultura e o da Educação. Essa união é histórica e relevante para as bibliotecas públicas, pois está mais de acordo com a missão delas e com os direitos à leitura e à informação, por natureza difusos, sobrepondo-se à organização tradicional do Estado. No documento de dezembro de 2006, com o texto conceitual e programático do PNLL, redimensionado e condensado pelo Estado e pelos representantes do livro e da leitura, as bibliotecas públicas são inseridas com veemência no que parece ter sido uma insistente exigência de grupos ligados a elas. Em mais de uma parte do texto, em que se lê, por exemplo, a expressão "uma política pública voltada ao livro e à leitura", destaca-se, imediatamente, embora entre parênteses: "e em particular, à biblioteca e à formação de mediadores". Nesse documento, as tarefas são assim divididas: a FBN seria a instância de debate e assessoria, e também de execução da política da área, enquanto a Secretaria de Políticas Culturais, (também do MINC) fica responsável pela coordenação e formulação das políticas.

\section{Os agentes institucionais}

Como visto no item anterior, com algum detalhamento, desde a recriação do Ministério da Cultura, no governo FHC, houve uma disputa entre diferentes instâncias do governo federal, na concepção e na execução de ações e políticas para as bibliotecas públicas. Se no PNLL, concretizado como documento no final do governo Lula, a distinção entre os diferentes agentes pelo menos foi explicitada, pode-se presumir, ainda 
assim, que muitos recursos, discussões e investimentos de pessoas e materiais foram dispersados, quando não desperdiçados, através dos governos, e mesmo dentro de cada um deles, por causa de confusão administrativa.

Essa acirrada disputa e seu vencedor (o MINC) levam a uma questão fundamental: a FBN deveria ou não ser a agente nacional das políticas para bibliotecas públicas? Em primeiro lugar, vale ressaltar que Biblioteca Nacional e biblioteca pública têm funções, acervo e usuários específicos e suas políticas de desenvolvimento partem de objetivos distintos. A submissão das bibliotecas públicas à Biblioteca Nacional pressupõe uma subordinação enganosa entre elas. No contexto do governo Collor, quando foi extinto o Ministério da Cultura, a BN foi a opção lembrada para dirigir o SNBP e o Proler, braços de uma política ainda não muito bem concebida para as bibliotecas públicas, mas que foi capaz de render seus próprios resultados. Porém, após a recriação do MINC, só mesmo uma desatenção administrativa justifica que aquelas funções tenham permanecido na FBN ao mesmo tempo em que outras, sobrepostas e concorrentes, passassem a ser desenvolvidas diretamente dentro do Ministério.

Nossa análise sugere, em defesa da própria grandeza e dignidadeda FBN, que tais funções sejam mesmo retiradas da Fundação, não só por que elatem funções ${ }^{10}$ por demais grandiosas e relevantes para o País, mas também por queo MINC, mais consolidado, já pode ter estrutura administrativa para planejar e executar as políticas, evitando disputas e guerras de vaidades, demasiado comuns na política brasileira, que em nada favorecem nem a FBN nem o SNBP.

Além disso, o distanciamento entre as tarefas de formulação e implementação dos programas (aqui, divididos entre dois órgãos diferentes) é apontado pelos estudiosos das políticas públicas, como um de seus mais sérios problemas gerenciais. Entretanto, a manutenção do Proler e do SNBP obviamente tem sentido, como principais vertentes de uma política para bibliotecas públicas no Brasil, por motivos já expostos.

Outra questão sobre as agências de políticas para a leitura e as bibliotecas no País é a confusão de nomenclaturas e de siglas, até dentro de documentos de um próprio governo. Alguns exemplos: a Secretaria do Livro e da Leitura (SLL), criada dentro do MINC no governo Fernando Henrique, transformou-se em Secretaria Nacional do Livro e da Leitura (SNLL) do mesmo ministério, no governo Lula, sem nenhuma justificativa plausível $^{11}$; (Setorial do Livro e da Leitura (CSLL), do governo Lula, inicialmente seria Câmara Setorial do Livro, da Literatura e da Leitura (CSLLL). A confusão administrativa entre programas, setores, diretorias e presidências, aliada à confusão de nomes e siglas, pode indicar, simbolicamente, uma falta de direção clara, integrada e inequívoca.

\footnotetext{
${ }^{10}$ Entre as funções mais universais: a organização e conservação do acervo bibliográfico nacional; o controle bibliográfico nacional; a disseminação, pormeio da Bibliografia Nacional e de outros produtos, do patrimônioacumulado; e o fornecimento de material para pesquisa.

${ }^{11}$ A SNLL foi extinta apenas cinco meses após a mudança, quando morre o ocupante da Secretaria, e suas funções vão para a FBN -que, afinal, já exercia as mesmas funções.
} 


\section{Os agentes humanos}

Em todas as políticas no período estudado, o desenvolvimento de pessoal, principalmente para a execução final das políticas, não foi ressaltado. O Proler incluiu em sua prática reuniões nas diversas regiões do Brasil para discussão e estudo sobre as práticas de leitura. Alguns desses grupos resistem até hoje. Do lado do SNBP e do MINC, mais tarde, as preocupações estiveram muito mais ligadas à distribuição de acervo do que à formação de pessoas para trabalhar, pensar e desenvolver serviços nas bibliotecas instaladas. Não foi constatada, em todo o período estudado, outra iniciativa como o Programa de Treinamento Intensivo para auxiliares de bibliotecas (PROTIAB) do INL, que oferecia capacitação não só nas técnicas bibliotecárias, mas também na atuação sociocultural dos auxiliares.

\section{Bibliotecas públicas dentro das políticas de informação}

Em termos conceituais, as políticas para bibliotecas são consideradas políticas horizontais, que integram políticas de informação mais gerais. Considerando a definição de teóricos como Aldo Barreto (2004) e retomando as discussões feitas na Europa e América latina sobre o papel das bibliotecas na Sociedade da Informação, entende-se que as bibliotecas públicas devem se integrar, também, às políticas nacionais de informação. No Brasil, contudo, tais políticas revestiram-se, de concepções diversas: numa época de ditadura, a política de informação visava o controle da informação e dos indivíduos pelo governo; já dentro de uma configuração democrática, a política de informação foi posta como um modo de assegurar o controle e a disseminação de informações consideradas estratégicas para o crescimento econômico (informações científicas e tecnológicas, principalmente). Assim, as bibliotecas públicas tangenciaram as políticas de informação, sem chegarem a integrá-las, de fato.

\section{Outros problemas das políticas públicas para bibliotecas}

As pesquisas de avaliação de políticas públicas no Brasil apontam para uma série de problemas que seriam os mais comuns, e aqui serão enumerados aqueles que também se apresentaram como problemas das políticas para bibliotecas. A cobertura dos programas é um problema que atinge, as políticas estudadas, em alguns aspectos: tanto quando o governo utiliza leis de incentivo em que o mercado define onde vai investir como, quando o governo transfere a liderança para organizações nãogovernamentais ou outras entidades, também pode haver uma justificada concentração pois: nos municípios mais pobres, desprovidos de classe política esclarecida e motivada, os programas simplesmente desaparecem, já que os habitantes têm pouca condição de se organizarem e defenderem seus direitos. 
A má qualidade dos serviços prestados coincide com a concentração descrita no item anterior: em geral quanto mais afastada e desassistida a população, piores os serviços oferecidos pela biblioteca pública, com raras exceções em que organizações da sociedade civil de fora do município promovem ações superiores ao grau de organização da população do lugar. O grau de privatização dos programas é outro problema, pois os diversos benefícios, oferecidos pelo último governo estudado, por exemplo, foram para a cadeia produtiva do livro, mais do que propriamente à população do País.

O problema da baixa participação dos beneficiários, reais ou potenciais, nas diferentes fases do programa, também pode ser destacado como outro problema. Desde a instituição do Proler foram promovidas reuniões em diferentes estados, mas as dimensões do País impedem que essa capilaridade seja alcançada diretamente pelo governo federal. No governo Lula, os meios eletrônicos foram citados várias vezes como fatores de garantia de participação, mas, sem que seja necessário enumerar os dados concentradores dos recursos eletrônico-digitais ${ }^{12}$, pode-se afirmar que boletins distribuídos por e-mail e vídeo conferências que se utilizam dos modernos recursos das TICs não podem, definitivamente, ser considerados veículos de popularização de informações e de democratização das instâncias decisórias das políticas públicas na década em que foi proposta.

A centralização na formulação, implementação e na organização administrativa dos programas e também no processo político é outro problema presente nas políticas estudadas. O uso político ou clientelista do programa para fins eleitorais e/ou de apoio político é uma prática demasiadamente disseminada no País, onde a inauguração e até a reinauguração de qualquer coisa é prática comum nas campanhas eleitorais, em todos os níveis. Por outro lado, como os frutos das políticas para bibliotecas públicas não se colhem em curto prazo, elas se tornam pouco interessantes para as campanhas eleitoreiras, que precisam apresentar realizações de eventos com resultados mais imediatistas. Um último problema, a falta de integração entre as agências na implementação dos programas, já foi devidamente tratada item anteriormente nesta seção.

\section{Considerações finais}

As políticas públicas de leitura e de informação podem se configurar de várias formas, de modo contínuo ou não, mais ou menos coerente e consciente, encorajando ou reprimindo ações. Sabe-se que essas políticas ainda são fundamentais para os países e não exclusivamente de países periféricos, constituindo-se uma centralidade no mundo atual, como a educação regular em todos os níveis.

Nosso trabalho reafirma a crença em um Estado que talvez não possa jamais voltar a ser aquele Estado que desempenhou, no passado,

\footnotetext{
${ }^{12}$ Compatíveis, de resto, com a conhecida concentração de riquezas e nível de desigualdade do país.
} 
um papel muito mais condutor e dirigente - embora nunca tenha garantido, de fato, o bem comum da maioria da população -, mas que de qualquer forma não pode se abster de promover esse mesmo bem comum, a despeito do discurso tão disseminado sobre o "Estado mínimo".

A democracia brasileira tem evoluído, num ritmo sempre mais lento do que carece a história brasileira de desigualdades, mas cuja lentidão também é um preço do próprio processo democrático. No âmbito das bibliotecas públicas, os quatro governos pesquisados neste trabalho avançaram e recuaram, mostrando sempre quais são as forças mais poderosas no jogo político.

Do ponto de vista de sua concepção e mesmo de sua construção, o PNLL é inédito na história do País. Contudo, cabe ao intelectual indagar ainda uma vez: será nossa "classe" política suficientemente esclarecida e republicana, que consiga vencer sua histórica limitação e superar governos e divisões partidárias (tão efêmeras, diga-se) ultrapassando-os, em prol do benefício coletivo e do dever histórico? De outra parte, estarão as lideranças da área educacional e bibliotecária, convictas, atentas e unidas, de modo a continuarem se pronunciando e contribuindo para a consolidação e o aprimoramento dessa política?

É necessário que haja um "pacto" suprapartidário, um compromisso dos políticos e da sociedade, um comprometimento em seguir as metas, independente dos resultados de eleições e da saudável alternância democrática dos grupos no poder. A política pública para bibliotecas no Brasil praticamente está engatinhando, em relação ao que deveria e até ao que poderia ser, mas não retrocedeu. Como as próprias bibliotecas, contudo, continuam urgentes e imprescindíveis.

\section{Referências}

ALMEIDA JÚNIOR, Oswaldo Francisco. Biblioteca pública: avaliação de serviços. Londrina: Eduel, 2003. 289p.

ARAÚJO, Eliany Alvarenga de. A palavra e o silêncio: biblioteca pública e Estado autoritário no Brasil. João Pessoa: Autor Associado/Ed. Universitária, 2002. 99p.

BARRETO, Aldo de Albuquerque. Políticas nacionais de informação. In: ENCONTRO NACIONAL DE CIÊNCIA DA INFORMAÇÃO, 5., 2004, Salvador. Anais... Disponível em: <http://www.cinform.ufba.br/v_anais/palestras/polinforma.ppt>. Acesso em: 30 jan. 2008.

BARROS, Paulo. A biblioteca pública e sua contribuição social para a educação do cidadão. Ijuí: Ed. Unijuí, 2002. 200p.

BATTLES, Matthew. A conturbada história das bibliotecas. São Paulo: Planeta do Brasil, 2003. 239p.

CESARINO, Maria Augusta da Nóbrega (Org.). Bibliotecas públicas municipais: orientações básicas. Belo Horizonte: Secretaria de Estado da Cultura, Superintendência de Bibliotecas Públicas, 2007. 223p. 
CUNHA, Vanda Angélica da. A biblioteca pública no cenário da Sociedade da Informação. Biblios Revista Electrónica de Bibliotecología, Archivología y Museología, Lima, v. 4, n. 15, p. 67-76, abr./jun. 2003.

FUNDAÇÃO BIBLIOTECA NACIONAL. Biblioteca pública: princípios e diretrizes. Rio de Janeiro: Fundação Biblioteca Nacional, 2000. 160p.

HAPEL, Rolf. Bibliotecas públicas: serão os seus fundamentos ainda válidos na sociedade? In: CONFERÊNCIA INTERNACIONAL BIBLIOTECAS PÚBLICAS: INVENTANDO O FUTURO, 2000, Lisboa. Comunicações... Disponível em: <http://www.iplb.pt/pls/diplb/!get_page?xid=930>. Acesso em: 25 maio 2007.

IFLA/UNESCO. Manifesto da IFLA/UNESCO sobre bibliotecas públicas 1994. Disponível em: <http://www.ifla.org/VII/s8/unesco/port.htm> Acesso em: 10 jun. 2007.

LEMOS, Antonio Agenor Briquet de. Bibliotecas. In: CAMPELLO, Bernadete, CALDEIRA, Paulo da Terra (Org.). Introdução às fontes de informação. Belo Horizonte: Autêntica, 2005. p. 101-119.

MACDERMOTT, Norma. Novas oportunidades na Sociedade da Informação. In: CONFERÊNCIA INTERNACIONAL BIBLIOTECAS PÚBLICAS: INVENTANDO O FUTURO, 2000, Lisboa. Comunicações... Disponível em: <http://www.iplb.pt/pls/diplb/!get_page?xid=930>. Acesso em: 25 maio 2007.

MILANESI, Luís. O que é biblioteca. 9. ed. São Paulo: Brasiliense, 1993. $108 p$.

MORAES, Rubem Borba de. Livros e bibliotecas no Brasil colonial. 2. ed. Brasília: Briquet de Lemos Livros, 2006. 259p.

MUELLER, Susana P. M. Bibliotecas e sociedade: evolução da interpretação e função e papéis da biblioteca. Revista da Escola de Biblioteconomia da UFMG, Belo Horizonte, v. 13, n. 1, p. 7-54, mar, 1984.

NOGUEIRA, Maria Cecília Diniz. Biblioteca pública: a contradição de seu papel. 1985. 108 f. Dissertação (Mestrado em Biblioteconomia)-Escola de Biblioteconomia, Universidade Federal de Minas Gerais, Belo Horizonte, 1985.

OLIVEIRA, Zita Catarina Prates. A biblioteca fora do tempo: políticas governamentais de bibliotecas públicas no Brasil, 1937-1989. 1994. Tese (Doutorado em Comunicação)-Universidade de São Paulo, São Paulo, 1994.

PAIVA, Marília de Abreu Martins de. Bibliotecas públicas: políticas do Estado brasileiro de 1990 a 2006. 2008. 140p. Dissertação (Mestrado)Universidade Federal de Minas Gerais, Escola de Ciência da Informação, Belo Horizonte, 2008.

SERRAI, A. A. A história das bibliotecas como evolução de uma idéia e de um sistema. Revista da Escola de Biblioteconomia da UFMG, Belo Horizonte, v. 4, n. 2, p. 141-161, set. 1975. 
SPERRY, Suzana. A verdade oculta na população sobre a biblioteca pública: solução para revisar seu papel. Revista da Escola de Biblioteconomia da UFMG, Belo Horizonte, v. 22, n. 2, p. 168-180, jul./dez. 1993.

SUAIDEN, Emir José. A biblioteca pública no contexto da Sociedade da Informação. Brasília: Ciência da Informação, Brasília, v. 29, n. 2, p. 5260, maio/ago. 2000.

UNIÃO EUROPÉIA. Comissão para a Cultura, a Juventude, a Educação e os Meios de Comunicação Social. Relatório A4-0248/98 sobre o papel das bibliotecas na sociedade moderna. 1998. Disponível em: <http://www.europarl.europa.eu/sides/getDoc.do?pubRef=-

//EP//TEXT+REPORT+A4-1998-

0248+0+DOC+XML+V0//PT\&language=PT>. Acesso em: 07 dez. 2007. 